\title{
Evaluation of Quality of Life in Diabetic Population with and without Diabetic Polyneuropathy
}

\author{
Manoj Abraham M ${ }^{1}$, Hari Hara Sudan $S^{2}$, Pavithra $V^{3}$ \\ ${ }^{1}$ Principal, KG College of Physiotherapy (Affiliated to The TN Dr MGR Medical University), KG Hospital \& \\ PG Medical Institute, Coimbatore. Tamil Nadu, India, ${ }^{2}$ Associate Professor, ${ }^{3}$ Assistant Professor, KG College \\ of Physiotherapy (Affiliated to The TN Dr MGR Medical University), KG Hospital \& PG Medical Institute, \\ Coimbatore. Tamil Nadu, India
}

\begin{abstract}
Background: Diabetes is a chronic, metabolic disease characterized by elevated levels of blood glucose, which leads over time to serious damage to the heart, blood vessels, eyes, kidneys and nerves. The complications of the Diabetes such as Diabetic Poly Neuropathy impacts the patient's Quality of Life, later may result in early death.

Methods: A total of 260 samples were taken and divided into 3 groups, Diabetes with DPN (G1), Isolated DM (G2), and Controls (G3) with 65, 65 and 130 samples respectively. They were assessed for Quality of Life with WHOQOL-BREF Questionnaire. Data were collected and taken for analysis. The overall WHOQOL-BREF scores of the three groups were $83.86 \pm 5.93,92 \pm 6.75$ and $98.33 \pm 0.94$ respectively. There was a significant statistical difference in WHOQOL-BREF in G1, G2 and G3 ( $\mathrm{p}=0.000$ ), but there was no significant statistical difference in WHOQOL-BREF in between G2 and G3 $(p=0.847)$ in domain 2 .

Conclusion: The findings in this study showed that the Quality of Life is reduced in patients with Diabetes mellitus with and without Diabetic Poly Neuropathy when compared with Controls without any metabolic disorders including Diabetes and without any types of associated Poly Neuropathy.
\end{abstract}

Key words: Diabetes Mellitus, Diabetic Poly Neuropathy, Quality of Life, WHOQOL-BREF

\section{Introduction}

Diabetes Mellitus (DM) is a chronic metabolic disorder characterized by persistent hyperglycemia ${ }^{[1]}$. It may be due to impaired insulin secretion, resistance to peripheral actions of insulin or combination of both. According to the International Diabetes Federation (IDF), approximately 415 million adults between the ages of 20 to 79 years had Diabetes Mellitus in $2015^{[2]}$.

\section{Corresponding author:}

Dr. Manoj Abraham M

Address- 69-1, Periyasamy Layout,

$5^{\text {th }}$ Cross, Rathinapuri, Coimbatore- 641027.

Email: manojpt3@gmail.com

Phone Number- 9600439512

ORCID $=0000-0002-7711-6461$
$\mathrm{DM}$ is providing to be a global public health burden as this number is expected to rise to another 200 million by the year 2040. Type 2 Diabetes is recognized as a serious public health concern with a considerable impact on human life and health expenditures. Causation of Diabetes is multi-factorial which includes genetic factors coupled with environmental influences such as obesity associated with rising living standards, steady urban migration, and lifestyle changes, which has resulted in a rapid increase in its prevalence ${ }^{[3-5]}$.

Diabetes affects individual's functional capacities and quality of life, leading to significant morbidity and premature mortality ${ }^{[6]}$. It causes a broad spectrum of neuropathic complications including acute and chronic forms affecting each level of peripheral nerve, from root to distal axon. One of the most common complications 
associated with Diabetes Mellitus is Diabetic Neuropath [7].

Diabetic Poly Neuropathy (DPN) is a leading cause for disability due to foot ulceration and amputation, gait disturbance and fall related injury. This complication is related to reduction in sensory and motor peripheral pathways, possibly due to abnormal neuromuscular response to postural disorders. It leads to an inability to detect temperature, vibration, pressure and proprioceptive changes, modifying the static and dynamic postural balance. In addition, it significantly reduce autonomy, individual and social well being, thus lowers the Quality of life that substantially increases the health costs associated with Diabetes and can even result in early death ${ }^{[8,9]}$.

The Quality of Life (QoL) derives from individual and subjective evaluation of each person's life, taking into account their perception of the physical, emotional and social well being ${ }^{[10]}$. World Health Organization (WHO) defined QoL as individual's perception of their position in life in the context of culture and value systems in which they live and in relation to their goals, expectations, standards and concerns. Therefore, except for person's physical health definition of QoL includes psychological state, level of person's independence, social life and personal beliefs ${ }^{[11]}$. For people living with $\mathrm{DM}$, disease management overload, co-morbidities and complications negatively affect QoL and studies show that QoL in diabetic patients is substantially decreased compared to individuals without Diabetes. Regular evaluation for QoL as a routine clinical practice could potentially improve necessary communication among the health care providers and their patients thereby identify the complications and help them for long care resulting in improving their health status ${ }^{[12]}$.

\section{Materials and Methodology}

This study was approved by the Institutional Ethical Clearance Certificate, Voluntary Health Services Hospital, Chennai. With Power Analysis, it was estimated to have 260 samples in 3 groups. A total of 130 subjects were identified who met the inclusion criteria and were part of the study. 65 subjects who were clinician diagnosed Type 2 Diabetes with Peripheral Neuropathy were assigned as Group1-G1 (DM with DPN). 65 subjects who were clinician diagnosed Type 2 Diabetes without Peripheral Neuropathy was assigned as Group2-G2 (Isolated DM). 130 subjects without any metabolic disorders including Diabetes and without any types of associated Poly Neuropathy who consented to take part in the study were assigned as Group3-G3 (Controls). Random Sampling technique was used to select the samples. Cluster Randomization was used to categorize the samples into respective groups. Other types of associated Poly Neuropathy were excluded. Written consent was obtained from the individuals and the permission was obtained from the Head of the institutions.

WHOQOL-BREF is an abbreviated version of WHOQOL-100, used to assess changes in quality of life. It consists of 26 questions and is based on 4 domain structures, which includes Physical health, psychological, social relationships and environment. This Questionnaire was used to assess the Quality of Life among the Diabetic patients with Diabetic Poly Neuropathy, without DPN and normal subjects without Diabetes and DPN. The data was collected and taken for analysis. A simple Mean and Standard Deviation is used to analyse the Demographic variables, ANOVA and multiple comparison test was used to analyse the data.

\section{Results}

Table I: Demographic Variables

\begin{tabular}{|l|l|l|l|l|l|}
\hline \multirow{2}{*}{ S.N } & \multicolumn{2}{|l|}{ Characteristics } & $\begin{array}{l}\text { G1 (DM with } \\
\text { DPN) } \\
\mathbf{n}=\mathbf{6 5}\end{array}$ & $\begin{array}{l}\text { G2 (Isolated DM) } \\
\mathbf{n}=\mathbf{6 5}\end{array}$ & $\begin{array}{l}\text { G3 (Controls) } \\
\mathbf{n}=\mathbf{1 3 0}\end{array}$ \\
\hline 1 & Age & $60.52 \pm 12.86$ & $67.85 \pm 7.77$ & $65.46 \pm 9.45$ \\
\hline \multirow{2}{*}{2} & \multirow{2}{*}{ Gender } & Female & $30(46.2 \%)$ & $32(49.2 \%)$ & $66(50.8 \%)$ \\
\cline { 2 - 6 } & & Male & $35(53.8 \%)$ & $33(50.8 \%)$ & $64(49.2 \%)$ \\
\hline
\end{tabular}


Cont... Table I: Demographic Variables

\begin{tabular}{|l|l|l|l|l|l|}
\hline 3 & Years of Formal education & $8.69 \pm 4.39$ & $8.34 \pm 4.37$ & $9.11 \pm 3.16$ \\
\hline \multirow{3}{*}{4} & \multirow{3}{*}{4} & Never married & $3(4.6 \%)$ & $5(7.7 \%)$ & $0(0 \%)$ \\
\cline { 3 - 6 } & \multirow{3}{*}{\begin{tabular}{l} 
Marital status \\
\cline { 3 - 6 }
\end{tabular}} & Currently married & $27(41.5 \%)$ & $34(52.3 \%)$ & $102(78.5 \%)$ \\
\cline { 3 - 6 } & Separated & $3(4.6 \%)$ & $4(6.2 \%)$ & $0(0 \%)$ \\
\cline { 3 - 6 } & Co morbidities & Widowed & $32(49.2 \%)$ & $22(33.8 \%)$ & $116(89.2 \%)$ \\
\cline { 3 - 6 } & & Present & $1(1.5 \%)$ & $56(86.2 \%)$ & $14(10.8 \%)$ \\
\hline
\end{tabular}

Table II ANOVA between the groups for each domain

\begin{tabular}{|l|l|l|l|l|l|}
\hline WHOQOL & $\begin{array}{l}\text { G1 (DM with DPN) } \\
\mathbf{n}=\mathbf{6 5}\end{array}$ & $\begin{array}{l}\text { G2 (Isolated DM) } \\
\mathbf{n}=\mathbf{6 5}\end{array}$ & $\begin{array}{l}\text { G3 (Controls) } \\
\mathbf{n}=\mathbf{1 3 0}\end{array}$ & $\mathbf{F}$ - ratio \\
\hline Domain 1 & $13.20 \pm 1.08$ & $14.63 \pm 1.73$ & $15.83 \pm 0.12$ & 160.485 & $0.000^{*}$ \\
\hline Domain 2 & $29.46 \pm 2.43$ & $31.94 \pm 2.14$ & $32.17 \pm 1.06$ & 28.409 & $0.000^{*}$ \\
\hline Domain 3 & $25.33 \pm 2.04$ & $27.6 \pm 2.78$ & $30.5 \pm 0.6$ & 231.003 & $0.000^{*}$ \\
\hline Domain 4 & $15.87 \pm 1.53$ & $17.83 \pm 2$ & $19.83 \pm 0.12$ & 303.735 & $0.000^{*}$ \\
\hline Total & $83.86 \pm 5.93$ & $92 \pm 6.75$ & $98.33 \pm 0.94$ & 223.451 & $0.000^{*}$ \\
\hline
\end{tabular}

*significant at $\mathrm{p}<0.05$

Table III Multiple Comparisons of WHOQOL-BREF scores between G1, G2 and G3

\begin{tabular}{|c|c|c|c|c|c|c|c|}
\hline \multirow{2}{*}{$\begin{array}{l}\text { Dependent } \\
\text { Variable }\end{array}$} & \multirow{2}{*}{$\begin{array}{l}\text { (I) } \\
\text { Group } \\
\text { (II) }\end{array}$} & \multirow{2}{*}{ (J) Group } & \multirow{2}{*}{$\begin{array}{l}\text { Mean } \\
\text { Difference } \\
\text { (I-J) }\end{array}$} & \multirow{2}{*}{$\begin{array}{l}\text { Std } \\
\text { Error }\end{array}$} & \multirow{2}{*}{ Sig. } & \multicolumn{2}{|c|}{ 95\% Confidence } \\
\hline & & & & & & $\begin{array}{l}\text { Lower } \\
\text { bound }\end{array}$ & $\begin{array}{l}\text { Upper } \\
\text { bound }\end{array}$ \\
\hline \multirow{3}{*}{ DOMAIN 1} & G3 & $\begin{array}{l}\text { G2 } \\
\text { G1 }\end{array}$ & $\begin{array}{l}.846^{*} \\
1.277^{*}\end{array}$ & $\begin{array}{l}.075 \\
.075\end{array}$ & $\begin{array}{l}0.000^{*} \\
0.000 *\end{array}$ & $\begin{array}{l}0.67 \\
1.10\end{array}$ & $\begin{array}{l}-8.33 \\
-13.80\end{array}$ \\
\hline & $\mathrm{G} 2$ & $\begin{array}{l}\text { G3 } \\
\text { G1 }\end{array}$ & $\begin{array}{l}.846^{*} \\
.431^{*}\end{array}$ & $\begin{array}{l}.075 \\
.087\end{array}$ & $\begin{array}{l}0.000^{*} \\
0.000 *\end{array}$ & $\begin{array}{l}1.02 \\
.23\end{array}$ & $\begin{array}{l}4.72 \\
-7.56\end{array}$ \\
\hline & G1 & $\begin{array}{l}\text { G3 } \\
\text { G2 }\end{array}$ & $\begin{array}{l}-1.277^{*} \\
-.431^{*}\end{array}$ & $\begin{array}{l}.075 \\
.087\end{array}$ & $\begin{array}{l}0.000 * \\
0.000 *\end{array}$ & $\begin{array}{l}-1.45 \\
-.64\end{array}$ & $\begin{array}{l}10.20 \\
3.40\end{array}$ \\
\hline \multirow{3}{*}{ DOMAIN 2} & G3 & $\begin{array}{l}\text { G2 } \\
\text { G1 }\end{array}$ & $\begin{array}{l}-.108 \\
1.354^{*}\end{array}$ & $\begin{array}{l}.196 \\
.196\end{array}$ & $\begin{array}{l}0.847 \\
0.000 *\end{array}$ & $\begin{array}{l}-.57 \\
.89\end{array}$ & $\begin{array}{l}-1.00 \\
-1.52\end{array}$ \\
\hline & G2 & $\begin{array}{l}\text { G3 } \\
\text { G1 }\end{array}$ & $\begin{array}{l}.108 \\
1.462 *\end{array}$ & $\begin{array}{l}.196 \\
.226\end{array}$ & $\begin{array}{l}0.847 \\
0.000 *\end{array}$ & $\begin{array}{l}-.35 \\
.95\end{array}$ & $\begin{array}{l}0.51 \\
-0.80\end{array}$ \\
\hline & G1 & $\begin{array}{l}\text { G3 } \\
\text { G2 }\end{array}$ & $\begin{array}{l}-1.354 * \\
-1.462 *\end{array}$ & $\begin{array}{l}.196 \\
.226\end{array}$ & $\begin{array}{l}0.000^{*} \\
0.000^{*}\end{array}$ & $\begin{array}{l}-1.82 \\
-2.00\end{array}$ & $\begin{array}{l}1.03 \\
0.24\end{array}$ \\
\hline
\end{tabular}


Cont... Table III Multiple Comparisons of WHOQOL-BREF scores between G1, G2 and G3

\begin{tabular}{|c|c|c|c|c|c|c|c|}
\hline \multirow{3}{*}{ DOMAIN 3} & G3 & $\begin{array}{l}\mathrm{G} 2 \\
\mathrm{G} 1\end{array}$ & $2.562 * 3.808 *$ & .188 .188 & $\begin{array}{l}0.000^{*} \\
0.000^{*}\end{array}$ & 2.123 .36 & $\begin{array}{l}-0.0852 \\
-0.4237\end{array}$ \\
\hline & $\mathrm{G} 2$ & $\begin{array}{l}\text { G3 } \\
\text { G1 }\end{array}$ & $-2.562 * 1.246^{*}$ & . 217 & $\begin{array}{l}0.000^{*} \\
0.000^{*}\end{array}$ & $\begin{array}{l}-3.01 \\
.73\end{array}$ & $\begin{array}{l}-0.0852 \\
-0.4369\end{array}$ \\
\hline & G1 & $\begin{array}{l}\text { G3 } \\
\text { G2 }\end{array}$ & $\begin{array}{l}-3.808^{*} \\
-1.246\end{array}$ & .188 .217 & $\begin{array}{l}0.000^{*} \\
0.000^{*}\end{array}$ & $\begin{array}{l}-4.25 \\
-1.76\end{array}$ & $\begin{array}{l}0.2532 \\
0.2401\end{array}$ \\
\hline \multirow{3}{*}{ DOMAIN 4} & G3 & $\begin{array}{l}\mathrm{G} 2 \\
\mathrm{G} 1\end{array}$ & $1.646 * 2.600^{*}$ & .111 .111 & $\begin{array}{l}0.000^{*} \\
0.000^{*}\end{array}$ & 1.392 .34 & $\begin{array}{l}0.8306 \\
-1.5230\end{array}$ \\
\hline & $\mathrm{G} 2$ & $\begin{array}{l}\text { G3 } \\
\text { G1 }\end{array}$ & $-1.646 * .954 *$ & .111 .128 & $\begin{array}{l}0.000^{*} \\
0.000^{*}\end{array}$ & $\begin{array}{l}-1.91 \\
.65\end{array}$ & $\begin{array}{l}0.5232 \\
-0.8698\end{array}$ \\
\hline & G1 & $\begin{array}{l}\text { G3 } \\
\text { G2 }\end{array}$ & $\begin{array}{l}-2.600^{*} \\
-.964 *\end{array}$ & .111 .128 & $\begin{array}{l}0.000^{*} \\
0.000^{*}\end{array}$ & $\begin{array}{l}-2.86 \\
-1.86\end{array}$ & $\begin{array}{l}1.2155 \\
0.5148\end{array}$ \\
\hline
\end{tabular}

*significant at $\mathrm{p}<0.05$

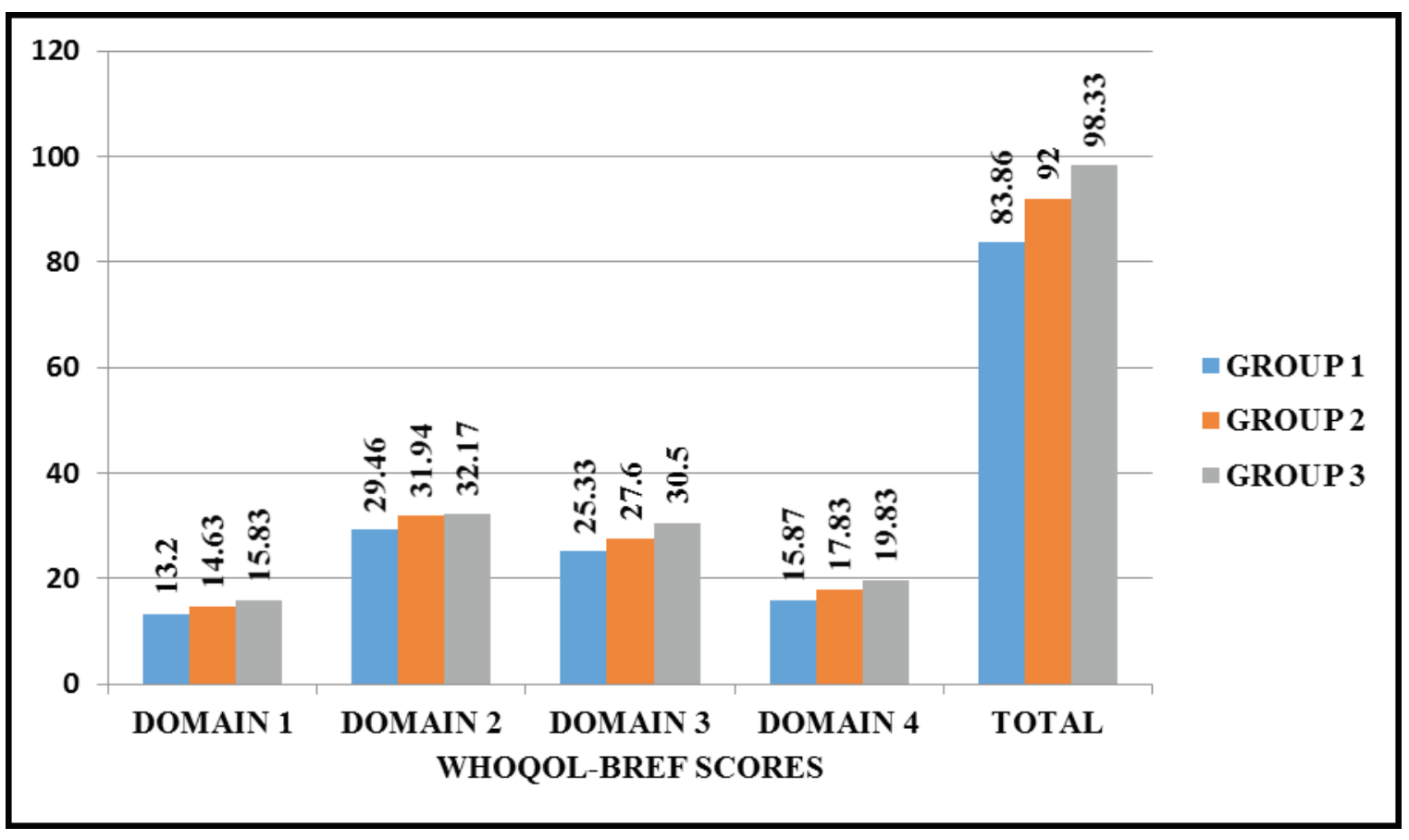

The overall WHOQOL mean scores in G1 was $83.86 \pm 5.93$, in G2 was $92 \pm 6.75$ and in G3 was 98.33 \pm 0.94 . There was a significant statistical difference in WHOQOL-BREF in G1, G2 and G3 ( $\mathrm{p}=0.000)$. Table I describes about the demographic variables which included the Age, Gender, years of formal education, marital status and co morbidities. Table II describes the Means and Standard Deviations for each Domain in WHOQOL-BREF in all three groups along with $\mathrm{F}$ - ratio was $160.485,28.409,231.003$ and 303.735 respectively. Table III shows the multiple comparisons of WHOQOL-BREF scores among the groups. There 
was a significant statistical difference in the WHOQOLBREF in the groups $\mathrm{G} 1, \mathrm{G} 2$ and $\mathrm{G} 3(\mathrm{p}=0.000)$, but there was no significant statistical difference in WHOQOLBREF in between $\mathrm{G} 2$ and $\mathrm{G} 3$ ( $\mathrm{p}=0.847)$ in domain 2 .

\section{Discussion}

As a part of decision making process, Quality of Life is often proxy judged without specifically asking the patient about it. Since these judgments can influence the choice of treatment, it is important to know if they are in concordance with patient's assessments. This is especially true for the management of chronic diseases such as Diabetes, whereby self-management of care can be a real burden for patients with the condition ${ }^{[13]}$.

In this study, Quality of Life among the patients with Diabetes mellitus with and without Diabetic Poly Neuropathy when compared with controls assessed with WHOQOL-BREF, showed a significant change in each domain, i.e., Physical health, Psychological, Social relationships and Environment. The WHOQOL-BREF scores were lower in groups G1 (DM with DPN), G2 (Isolated DM) than in group G3 (Controls) in domains D1, D3, and D4. Only in domain D2, there is no difference between groups G2 and G3.

Patients with Diabetes have worse Quality of Life compared to persons without Diabetes, especially those with diabetic neuropathy ${ }^{[14]}$. The Physical domain of QoL might be decreased because of the presence of comorbidities such as Hypertension, Cervical Spondylitis, Osteoarthritis, Low back pain and Periarthritis shoulder. Studies also reported that presence of co-morbidities as a predictor of poor QoL. The diabetic patients without complications had a better QoL compared to the patients with diabetic complications and as the number of complications increased the QoL score decreased ${ }^{[15]}$.

It is known that depression has a harmful impact on glycemic control and in turn, poorly controlled diabetes intensifies depressive symptoms and has a potentially significant impact on QoL ${ }^{[16]}$. Not only depression but also changes in the perception about the feelings and the self image of individual can significantly reduce their QoL. Surprisingly in this study we did not find any change in Domain 2 i.e., Psychological, between the patients with isolated Diabetes mellitus (G2) and controls (G3). They showed better scores in domain 2, than in patients with Diabetes mellitus with Diabetic Poly Neuropathy (G1).

The impact of the disease and of treatment on all chronic patients QoL and lifestyle is a key concern for both the patients themselves and their physicians. This is particularly relevant in the case of diabetic patients: the physical, psychological and social burden of diabetes affects patient's self care behaviours, disease management, therapeutic adherence and consequently QoL ${ }^{[17]}$.

With advancement of age, the number of complications and incapacities increases, leading to a decrease in the autonomy that influences quality of life. In general, studies already performed suggest that the presence of chronic complications of DM is associated with significant decrease in the quality of life of individuals with DM, and the quality of life decreases as the number of chronic complications increases ${ }^{[18,19]}$.

\section{Conclusion}

The findings in this study showed that the Quality of Life is reduced in patients with Diabetes mellitus with and without Diabetic Poly Neuropathy when compared with Controls without any metabolic disorders including Diabetes and without any types of associated Poly Neuropathy. It is recommended that Quality of Life has to be regularly evaluated in the chronic diseases, so that their health status can be improved and treated accordingly to avoid complications.

Acknowledgement: The Authors sincerely thank Dr. Ennapadam S Krishnamoorthy, Founder and Chief Consultant of NeuroKrish, Chennai, and the Expert team members for their support and logistical help to conduct this research.

Funding: No funding was received for conducting this study

Conflict of Interest: The authors have no conflict of interest to declare that are relevant to the content of this article

\section{References}

1. Goyal R. Jialal I. Diabetes mellitus Type 2.Ini StatPearls. StatPearls Publishing, Treasure Island (FL);2019 
2. Zheng Y, Ley SH, Hu FB. Global etiology and epidemiology of type 2 diabetes mellitus and its complications. Nat Rev Endocrinol. 2018, Feb;14(2): 88-98

3. Onyango EM, Onyango BM. The rise of noncommunicable diseases in Kenya: An examination of the time trends and contribution of the changes in diet and physical inactivity. J Epidemiol Glob Health.2018 Dec; 8(1-2); 1-7

4. Aditya Oruganti, Avinash Kavi, Padmaja R Walvekar. Risk of developing Diabetes Mellitus among urban poor South Indian population using Indian Diabetes Risk Score, J Family Med Prim Care, 2019, Feb; 8(2): 487-492

5. Kaveeshwar SA, Cornwall J. The current state of diabetes mellitus in India. Australas Med J 2014;7:45-8.

6. Ramtahal R, Khan C, Maharaj-Khan K, Nallamothu S, Hinds A, Dhanoo A, Yeh HC, Hill-Briggs F, Lazo M. Prevalence of self reported sleep duration and sleep habits in type 2 diabetes patients in South Trinidad. J Epidemiol Glob Health.2015 Dec; 5(4 supply 1): S35-43

7. Juster Switlyk K, Smith AG. Updates in Diabetic Peripheral Neuropathy. F1000Res. 2016; 5: F1000Faculty Rev-738. Published 2016 Apr 25. doi:10.12688/f1000research.7898.1

8. Tesfaye S: Diabetic Neuropathies: Update on Definitions, Diagnostic Criteria, Estimation of severity and Treatments. Diabetes Care, 2010 Oct, 33(10): 2285-2293

9. Ernandes RC, Brech GC, Luna NMS, Bega A, Guimarães DS, Bocalini DS, Scherrer G Jr., Greve JM, Leme LEG, Alonso AC. The impact of diabetic neuropathy on quality of life and postural balance in Brazilian older adults. Acta Ortop Bras. [online]. 2020;28(6):275-279. Available from URL: http:// www.scielo.br/aob.

10. Jorgetto JV, Franco LJ. Evaluation of the quality of living of individuals with diabetes mellitus through the use of WHOQOL-100. J Clin Endocrinol Res. 2018; 1(1): 17-23

11. The World Health Organization Quality of Life Assessment (WHOQOL): Development and General psychometric properties. Soc Sci Med. 1998 Jun; 46(12):1569-85
12. Prajapati VB, Blake R, Acharya LD, Seshadri S, Assessment of Quality of Life in type II diabetic patients using the modified diabetes quality of life (MDQoL) - 17 questionnaire. Braz J Pharm Sci, 2017; 53(4)

13. Stanislava Yordanovaa, Valentina Petkovaa , Guenka Petrovaa, Milen Dimitrova , Emilia Nasevab , Maria Dimitrovaa and Elina Petkova, Comparison of health-related quality of life measurement instruments in Diabetic patients, Biotechnology and Biotechnological Equipment, 2014,28(4):769-774

14. Uazman Alam, Asher Fawwad, Fariha Shaheen, Bilal Tahir, Abdul Basit, and Rayaz A. Malik, Improvement in neuropathy specific quality of life in patients with Diabetes after Vitamin-D supplementation. Journal of Diabetes Research, 2017, Article ID 7928083, doi. org/10.1155.2017/7928083

15. Jiménez-Garcia R, Jiménez-Trujillo I, HernandezBarrera V, Carrasco-Garrido P, Lopez A, Gil A. Ten-year trends in self-rated health among Spanish adults with diabetes, 1993-2003. Diabetes Care. 2008;31(1):90-2.

16. Paula Cristina Couras Corrêa , Leilane Martins Farias , Guldemar Gomes de Lima , Adriano Rodrigues de Souza, Aline Rodrigues Feitoza, Ana Débora Assis Moura, Emilia Soares Chaves Rouberte, Perception of carries for at the Family health strategy, about diabetes mellitus type 2 . Rev. enferm. UFPE. 2017; 11(4):1645-51.

17. Lorenzo Palamenghi, Milvia Marta Carlucci, and Guendalina Graffigna, Measuring the QoL in Diabetic patients-A Journal of Diabetes Research, 2020, Article ID 5419298, https://doi. org/10.1155/2020/5419298

18. Esteves C. Quality of life of hypertensive and diabetic elderly in an outpatient clinic Quality of life of elderly people in a long-term institution. Arq Cienc Saúde. 2016; 23:36-40.

19. Gomes AR, Santos L. The prevalence of complications of diabetes mellitus in ACeS Santo Tirso/Trofa: a descriptive study. Rev Port Med General Fam. 2017; 33(4). 